\title{
Enzyme Catalyzed Study of Some Unsaturated Acids by N- Bromoisonicotinamide - A Kinetic Approach
}

\author{
Aparna Prajapati $^{1^{*}}$, Arvind Prasad Dwivedi ${ }^{2}$, Surendra Singh Parihar ${ }^{3}$ \\ ${ }^{I}$ Department of Chemistry, Govt. P.G. Girls College (NAAC) Rewa (M.P.) India \\ ${ }^{2}$ Department of chemistry, Govt. Sanjay Gandhi Smriti Auto.P.G.College, Sidhi M.P.India
}

*Corresponding Author: Aparna Prajapati, Department of Chemistry, Govt. P.G. Girls College (NAAC) Rewa (M.P.) India

\begin{abstract}
Enzyme cationic micelles cetyltrimethyl ammonium bromide (CTAB) catalysed oxidation of unsaturated acids viz., acrylic and $\alpha$-crotonic acid by halooxidant $N$-bromoisonicotinamide (NBIN) in aqueous acetic acid medium have been studied to afford corresponding products aldehydes. The reactions exhibit first-order kinetic with oxidant [NBIN] and fractional-order to concentration of unsaturated acids. The acid has shown negligible effect on rate. The study provides an evidence of complex formation between substrate and postulated species $\mathrm{H}_{2} \mathrm{O}^{+} \mathrm{Br}$ of the oxidant with stoichiometric ratio 1:2. The solvent polarity enhances the rate of oxidation whereas addition of enzyme CTAB attains almost limiting value of rate at its optimum concentration. A mechanism in consistent with the thermodynamic data and rate law have been proposed.
\end{abstract}

Keywords: Acrylic acid, a-crotonic acid, $\mathrm{N}$-bromoisonicotinamide, $\mathrm{H}_{2} \mathrm{O}^{+} \mathrm{Br}$, cetyltrimethyl ammonium bromide

\section{INTRODUCTION}

Micelles are enzyme catalysts, which are complex mixture of organic compounds mostly polymers treated as surfactant. The hydrophobic and electrostatic forces in presence of CTAB influence the rates of several oxidation reactions ${ }^{1}$. The enzyme catalysis possesses midway properties between homogeneous and heterogeneous catalysis. It is also called as micro heterogeneous catalyst. ${ }^{2-4}$ Aggregates of these micelles in CMC range are responsible for altering the rate of reaction in aqueous solution which is extremely temperature dependent.

$\mathrm{N}$-bromoisonicotinamide (NBIN) is a moderate and mild halooxidant showing antimicrobial activity. This is non-hazardous, consumes little time and easily to isolate the final products when employed after oxidation. The psycho-economic activity of this oxidant is limited and scanty. Recently, this oxidant has been used in the oxidative study of aliphatic alcohols ${ }^{5}$ and amino acids ${ }^{6}$ in lack of catalysts. The unsaturated acid contains $-\mathrm{COOH}$, carboxylic functional group with double bond plays an important role in several biochemical process occurring in all cellular respiration. The oxidations of unsaturated acids have been studied rather more extensively than other substituted carboxylic acids. Even with the same oxidant different mechanistic routes have been proposed although CTAB enzyme catalyst has been utilised in exploring the oxidation of primary alcohol ${ }^{7}$ and aldehydes. ${ }^{8}$ various authors have reported the oxidation kinetics of unsaturated acids employing different oxidants $\mathrm{KMnO}_{4}{ }^{9}, \mathrm{LTA}^{10}$ etc. However, no systematic kinetic work has been documented on NBIN oxidant. This prompted us to study the kinetic oxidation of acrylic and $\alpha$-crotonic acid with NBIN catalysed by enzyme CTAB, to understand and enlightended the complicated bio-chemical mechanism. ${ }^{11}$

\section{MATERiAl AND Methods}

All the chemical and solvents used in the studies are of analytic analaR grade. The NBIN was prepared in acetic acid $\mathrm{BDH}$ and its purity was checked iodometrically using $2 \% \mathrm{KI}$ solution in presence of $\mathrm{H}_{2} \mathrm{SO}_{4}$. The substrate's solution was prepared as mentioned in the literature. The kinetic study was initiated under the pseudo- first order condition [Substrate] $>$ [NBIN]. The micelle enzyme CTAB catalyst is of highest purity, available commercially was used under CMC condition. In kinetic run, the requisite amount of unsaturated acid (substrate) was taken in aqueous acetic acid in 
a reaction glass vessel placed in a water thermostat at the experimental temperatures $40^{\circ}$ for 40 minutes. The NBIN solution was taken in another flask kept in the same thermostat with an accuracy $\left( \pm 0.1^{\circ} \mathrm{C}\right)$, when both the solution attains, the same temperature, immediately, the reaction was followed by rapid addition of calculated amount of NBIN solution to the first vessel. The progress of the reaction was monitored by estimating the amount of unreacted oxidant at regular intervals of time iodometrically. ${ }^{\mathbf{1 2}}$

The observed data were fed in equation of integration method $(k=2.303 \log \quad \mathrm{a} / \mathrm{a}-\mathrm{x})$ for evaluation of observed rate constants. Replicate runs showed that rate constant were reproducible to within $\pm 3 \%$ precision.

\section{RESULTS AND DISCUSSION}

The stiochiometry of each reaction under probe has been determined separately by keeping the reaction $\mathrm{n}$ mixture at room temperature for 24 hours. The estimation of unconsumed NBIN overall showed 1:2 mole ratio. The stoichiometric equation may be represented as :

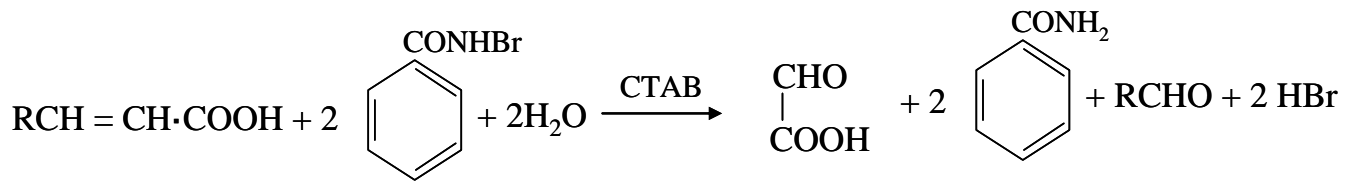

Where, $\mathrm{R}=-\mathrm{H}$ and $-\mathrm{CH}_{3}$ for acrylic and a-crotonic acid respectively.

Table1. Dependence of rate on the concentration of substrate

$10^{3} \times[\mathrm{NBIN}]\left(\mathrm{mol} \mathrm{dm}^{-3}\right)=2.50(1,2)$;

$10^{3} \times[\mathrm{CTAB}]\left(\mathrm{mol} \mathrm{dm}^{-3}\right)=1.00(1,2)$;

$\mathrm{CH}_{3} \mathrm{OOH}-\mathrm{H}_{2} \mathrm{O}, \%(\mathrm{v} / \mathrm{v})=30$ (1), 40 (2);

Temperature $\mathrm{K}=313(1,2)$

\begin{tabular}{|c|c|c|c|}
\hline \multirow[t]{2}{*}{ S. No. } & \multirow[t]{2}{*}{$10^{2} \times[$ Substrate $]\left(\mathrm{mol} \mathrm{dm}^{-3}\right)$} & \multicolumn{2}{|c|}{$10^{4} \mathrm{k}_{1}\left(\mathrm{~s}^{-1}\right) \longrightarrow$} \\
\hline & & Acrylic acid (1) & $\alpha$-crotonic acid (2) \\
\hline 1. & 1.25 & 2.19 & 2.78 \\
\hline 2. & 2.00 & 3.50 & 4.03 \\
\hline 3. & 2.50 & 3.85 & 4.62 \\
\hline 4. & 3.33 & 3.92 & 4.82 \\
\hline 5. & 4.00 & 3.82 & 4.92 \\
\hline 6. & 5.00 & 3.57 & 4.79 \\
\hline
\end{tabular}

1. Acrylic acid (AA) 2. a-crotonic acid (CA)




Table2. Effect of Solvent polarity on rate

$10^{2} \times[$ Substrate $]\left(\mathrm{mol} \mathrm{dm}^{-3}\right)=2.50(1), 2.0(2)$;

$10^{3} \times[\mathrm{NBIN}]\left(\mathrm{mol} \mathrm{dm}^{-3}\right)=2.50(1,2)$;

$10^{3} \times[\mathrm{CTAB}]\left(\mathrm{mol} \mathrm{dm}^{-3}\right)=1.00(1,2)$;

Temperature $\mathrm{K}=313(1,2)$

\begin{tabular}{|c|c|c|c|c|}
\hline \multirow[t]{2}{*}{ S. No. } & \multirow[t]{2}{*}{$\mathrm{CH}_{3} \mathrm{COOH} \%(\mathrm{v} / \mathrm{v})$} & \multirow[t]{2}{*}{$10^{3} / \mathrm{D}$} & \multicolumn{2}{|c|}{$10^{4} \mathrm{k}\left(\mathrm{s}^{-1}\right) \longrightarrow$} \\
\hline & & & Acrylic acid (1) & $\alpha$-crotonic acid (2) \\
\hline 1. & 20 & 17.17 & 3.44 & 3.61 \\
\hline 2. & 30 & 19.15 & 3.85 & 3.98 \\
\hline 3. & 40 & 21.98 & 4.02 & 4.13 \\
\hline 4. & 50 & 25.64 & 4.87 & 5.35 \\
\hline
\end{tabular}



The corresponding aldehydes and glyoxalic acid were found to be the main products of oxidation, confirmed by spectroscopic method and other methods too. The aldehydes were also confirmed by determining their melting points of 2:4-DNP derivatives. The kinetic data was collected at several concentrations of oxidant in 30 and $40 \%(\mathrm{v} / \mathrm{v})$ acetic acid in presence of enzyme catalyst (CTAB) at experimental temperature $40^{\circ} \mathrm{C}$. The plot of $\log (\mathrm{a}-\mathrm{x})$ versus time with unit slope exhibited first-order rate with respect to [NBIN]. The study indicated fractional-order kinetics when study was made by varying five-fold concentrations of unsaturated acids (Table 1). The order with respect to substrate varies from one to zero at their higher concentrations. The existence of complex formation between active species of oxidant $\mathrm{H}_{2} \mathrm{O}^{+} \mathrm{Br}$ and substrate was established by inverse plot of $\mathrm{k}$ and [substrate] ${ }^{-1}$ yields positive intercepts on Y-axis (Fig. 1). The rate of oxidation is slightly retarded by adding increasing concentration of $\mathrm{H}_{2} \mathrm{SO}_{4}$ showing fractional-order and its effect is almost negligible. The rate of reaction steadily increases by increasing the binary composition of acetic acid and water (Table 2). The linearity of Amis plot of $\log \mathrm{k}$ versus 1/D gave positive slope indicating that two dipoles ions are involved in the reaction (Fig. 2).

The rate of reaction is unaffected by addition of varying concentration of neutral salts $\mathrm{NaCl}$ and $\mathrm{KCl}$ which indicated that salt effect is negligible. The rate of reaction gradually inhibited by the successive addition of isonicotinamide, a reductant product of the reaction. The CTAB a micelles enzyme catalyst when added to the reaction mixture within $\mathrm{CMC}$ ranges initially catalyze the reaction at its optimum concentration attains a limiting value but rate declines when concentration of CTAB is increased. It is observed that CTAB leads a complex mechanism. 


\subsection{Mechanism}

In the present study, powerful remote active species of oxidant is $\mathrm{H}_{2} \mathrm{O}^{+} \mathrm{Br}$ which interact with the aliphatic unsaturated acids in the slow step, with the transfer of electron that occurs from substrate to active species during the formation of complex in a pre-equilibrium step. The study rules out the presence of free radicals in the reaction mixture when treated with acrylonitrile solution ignoring completely its participation in the reaction. Summing-up of experimental results, a probable mechanism for the oxidation of unsaturated aliphatic acids with NBIN, catalysed by enzyme CTAB could be proposed in following mode of scheme.

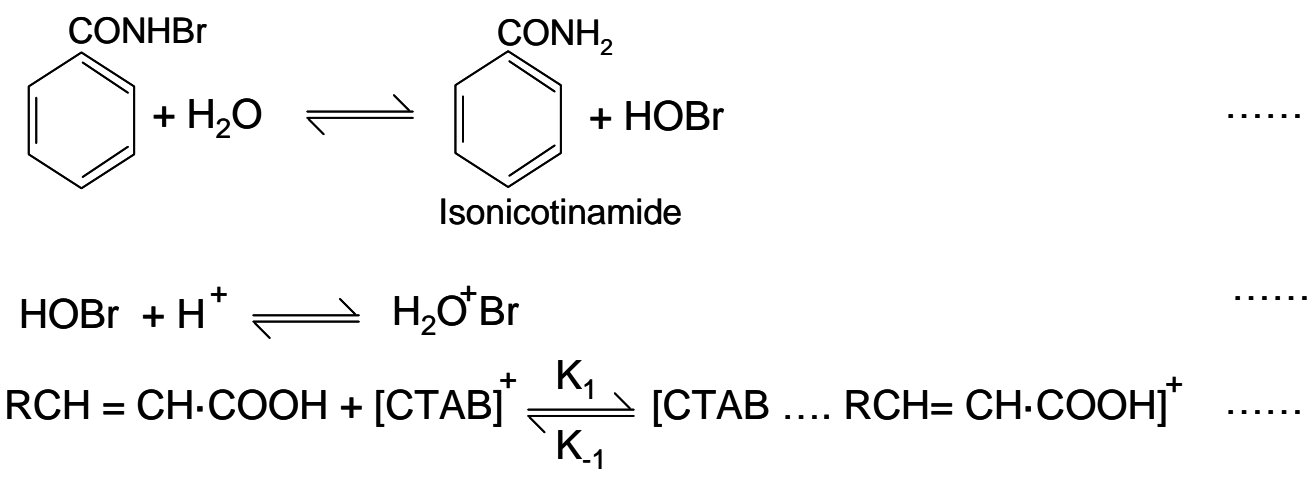

Where, $\mathrm{R}=-\mathrm{H},-\mathrm{CH}_{3}$ and for acrylic acid, a-crotonic acid respectively.

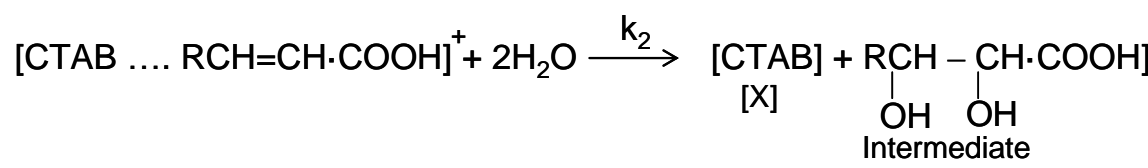

$$
\begin{aligned}
& \text { [C] }
\end{aligned}
$$

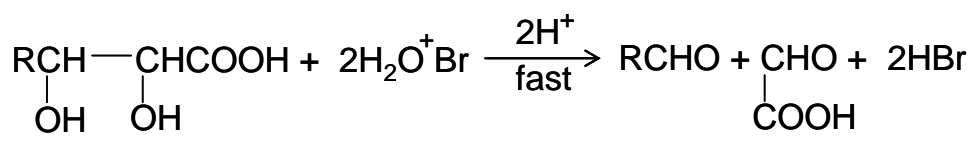

Step (4) is slow and rds of the reaction.

The final rate law was derived as:

$$
-\frac{\mathrm{d}\left[\mathrm{H}_{2} \mathrm{O}^{+} \mathrm{Br}\right]}{\mathrm{dt}}=\frac{\mathrm{K}_{2} \mathrm{~K}_{1}[\mathrm{CTAB}]_{\mathrm{T}}^{+}[\mathrm{S}]}{\left(\mathrm{K}_{-1}+\mathrm{K}_{2}\right)+\mathrm{K}_{1}[\mathrm{~S}]}
$$

Rate expression (6) apparently accounts for all the experimental facts satisfying the results. On assuming $\mathrm{K}_{2} \gg \mathrm{K}_{-1}$ and $\mathrm{K}_{1}[\mathrm{~S}]$ and neglecting the terms involved in denominator, the equation (6) reduces to:

$$
\frac{-d}{d t}\left[\mathrm{H}_{2} \mathrm{O}^{+} \mathrm{Br}\right]=\mathrm{k}_{1}[\mathrm{CTAB}]_{\mathrm{T}}^{+}[\mathrm{S}]
$$

Equation (7) also explains the experimental findings.

During the course of entire investigation in entitled reactions the lack of de-carboxylation was observed as $\mathrm{H}_{2} \mathrm{O}^{+} \mathrm{Br}$ species attacks at carbon double bond carbon which causes fission forming glyoxalic acid. The rate law shows that reactions follows the transition state which are highly solvated and cyclic in nature.

The observed order of reactivity was found in the sequence:

a-crotonic acid > Acrylic acid

The presence of $-\mathrm{COOH}$ functional group and double bond plays an important role in explaining the mechanism. The cationitic species $\mathrm{H}_{2} \mathrm{O}^{+} \mathrm{Br}$ attack at double bond $(\mathrm{C}=\mathrm{C})$ form complex causes fission to produce aldehyde and glyoxalic acid. According to study the electron donating group accelerates the rate of oxidation while electron attracting group retards the rate this suggests that the transition state must be electron deficient, the above order of reactivity is influenced by the structure molecular design of a-crotonic acid containing $\mathrm{CH}_{3}$ group, showing inductive effect. The above order of 
reactivity is further supported by activation parameters. The values of free energy of activation $\Delta \mathrm{G}^{\#}$ (87.25 to $\left.87.86 \mathrm{~kJ} / \mathrm{mole}^{-1}\right)$ and entropy $\Delta \mathrm{S}^{\#}\left(-96.47\right.$ to $\left.98.21 \mathrm{JK}^{-1} / \mathrm{mole}^{-1}\right)$ reveals that the activated complex formed at the transition state measures the randomness of the reaction. Over all, the reactions are enthalpy controlled.

\section{CONCLUSiON}

The study reveals, the limiting value of rate constant was obtained at optimum concentration of $\mathrm{CTAB}$, because of nature of junctural region of Gouy-Chapman-Stern layer of the miscelles. The complex formed at the transition state is not very rigid easily decomposes into the products which are identified by spectroscopic methods.

\section{REFERENCES}

[1] Joshi, Ghanat K., Katre, Y.R., and Singh, Ajaya Kumar, Journal of surfactant and detergents, 2006, Vol. 9, 231-235.

[2] Katre, Y.R., Joshi G.K and Singh A.K, Kinetika, Kataliz, Russian, 2009, Vol, 50, No.3, pp 380-396.

[3] Katre, Y.R., Joshi G.K and Singh A.K. Rai, Kinetics and Catalysis, 2009, Vol.50, No.3, 367-376.

[4] Patil, S., Katre Mathiyalagam, N., Balasubramaniyam, Journal of Surfactant and Detergents, 2007, Vol.10, No.3, 175-184.

[5] Michaelis, M.M. and Menton, M.L., Bio Chem. Z., 1913, 49, 333.

[6] Kavanau, J.L., Structure and function in biological Membranes, Sanfrancisco Holden- DAY, USA, 1965, Vol.1

[7] Rai, Abhishek Kumar and Nigam, S.K., Ph D. Thesis A.P.S. University, Rewa, 2007.

[8] Porte, G., Poggi, Y., Appell. J. and Moret, G.J., Phys. Chem. 1984, 88, 5703.

[9] Madhav Rao, B., Shashtry, T.P. and Prakash, T.S., Indian Sc. Cong.68 th session 80. 1981.

[10] Adamcikova, L. and Knappova, O, Czechoslovak. Academy of Sciences, 1983, 48, 2335.

[11] Shiravastava, R.P. and Rai, R.C., Journal Indian Chem. Soc., 1972, 49, 625.

[12] Barkat, M.Z., Abdel wahab. M.F., Analyt. Chem., 1954, 26, 973.

Citation: Aparna Prajapati., et.al, "Enzyme catalysed study of some unsaturated acids by $N$ bromoisonicotinamide - A kinetic approach", International Journal of Advanced Research in Chemical Science, vol. 6, no. 8, p. 1-5, 2019. DOI: http://dx.doi.org/10.20431/2349-0403.0608001

Copyright: () 2019 Authors. This is an open-access article distributed under the terms of the Creative Commons Attribution License, which permits unrestricted use, distribution, and reproduction in any medium, provided the original author and source are credited. 